\title{
Psycho-social stressors and life events of the patients with conversion disorder: a study in a tertiary care hospital in north east zone of Bangladesh
}

\author{
Susmita Roy, ${ }^{1}$ Gopi Kanta Roy, ${ }^{2}$ Momtaz Begum, ${ }^{3}$ Md Enayet Karim, ${ }^{4}$ Mst Shammy Akhter, ${ }^{5}$ Olita \\ Begum $^{6}$ \\ ${ }^{1}$ Associate Professor, Department of Psychiatry, Jalalabad Ragib Rabeya Medical College \& Hospital \\ (JRRMCH), Sylhet, Bangladesh; ${ }^{2}$ Professor and Head, Department of Psychiatry, JRRMCH, Sylhet, \\ Bangladesh; Associate Professor, Department of Medicine, JRRMCH, Sylhet, Bangladesh, ${ }^{5}$ Indoor Medical \\ Officer, Department of Psychiatry, JRRMCH, Sylhet, Bangladesh; Registrar, Department of Psychiatry, \\ JRRMCH, Sylhet, Bangladesh, ${ }^{6}$ Indoor Medical Officer, Department of Psychiatry, JRRMCH, Sylhet, \\ Bangladesh.
}

Article info
Received: 03 August 2016
Accepted : 03 Sept 2016
Number of tables : 03
Number of figures : 03
Number of refs. : 12
Correspondence:
Susmita Roy
Mobile: +8801711459277
E-mail:
Susmita07@hotmail.com

\section{Summary:}

The symptoms of conversion disorder arise in response to stressful situations. The objective of the study was to evaluate the frequency of various psychosocial stressors and socio-demographic characteristics in patients with Conversion disorder. This was a descriptive Cross sectional study conducted in the Department of Psychiatry of Jalalabad Ragib Rabeya Medical College Hospital, Sylhet, Bangladesh during the period from March 2011 to February 2013 among 240 admitted patients with conversion disorder satisfying inclusion and exclusion criteria who were consecutively selected as study group. This study revealed that the most of the patients $(62.5 \%)$ were below the age of 25 years with female predominance (90.4\%). Among the patients, $67.5 \%$ came from joint family, $62.1 \%$ from rural area and $71.7 \%$ from the families with income within 10,000-20,000 BDT per month. Also 62.5\% patients experienced seizure whereas $22.9 \%$ experienced mixed symptoms. Psychosocial stressors were clearly identified in $87.5 \%$ of the patients. The stressors in our population in order of frequency were disturbed relation with in-laws $(20.8 \%)$, failure in examination or study problem $(20 \%)$, disturbed relation with spouse $(15.4 \%)$, husband staying abroad (13.3\%), love problems (11.2\%), job stress or more work-load $(11.2 \%)$, relationship problem with family members or parents $(9.6 \%)$, pampered child $(3.3 \%)$, demand of marriage $(3.3 \%)$, marriage against will $(2.9 \%)$, death of a close family member $(2.1 \%)$, physical illness $(2.1 \%)$, demand of going abroad $(1.7 \%)$, issue less $(1.7 \%)$ and financial crisis $(1.2 \%)$. In this study, a large number of stressors were identified in patients with conversion disorder. The pattern of the stressors in our subjects was unique to our population and most of these stressors were easily treatable.

Bang J Psychiatry 2014,28(2):41-44

\section{Introduction}

The term "conversion' is introduced by Freud for a hypothetical mechanism by which psychological stressor leads to physical symptoms and conversion disorder defined as a condition that may results from conversion. In the Diagnostic and Statistical Manual of Mental Disorders, 4th edition (DSM-IV-TR), conversion disorders are included under the category of somatoform Disorders. It is a condition that in the past was called "hysteria'. Hysteria is one of the oldest Words in the medical vocabulary. It is derived from Greek word "hysterus' meaning wandering of uterus in the body. So it was believed that, hysteria was a disease of women. But Briquet and Charcot contributed to the development of the concept of conversion disorder. They noted association between the symptoms of conversion disorder and a traumatic event. Now it is suggested that conversion disorder develops as a reaction to emotional stress or conflict in the presence of a series of environmental, biological and personal vulnerability factors. As our society appreciate or accept the physical symptoms more, conversion disorder may be an adaptive way of expressing the difficulties faced by the person in the stressful situation.6Life events have attracted attention as possible triggers of neurosis and life events affect the premorbid personality also. Painful experiences such as death of a loved ones, divorce, medical illness or losing everything in a natural disaster can be so impactful as to trigger clinical depression as well as various somatic disturbances including conversion disorder. ${ }^{8}$ Evaluation of socio demographic, clinical characteristics and psychosocial stressors of patients suffering from conversion disorder will increase awareness among professionals and 
general population. Considering this fact, the present study was conducted with the aim to determine the frequency of various psychosocial stressors and sociodemographic characteristics in patients with conversion disorder. Findings of this study will provide baseline information to stimulate further studies as well as be helpful for the development of awareness.

\section{Materials and methods}

This descriptive cross sectional study was conducted in Jalalabad Ragib Rabeya Medical College Hospital, Sylhet, Bangladesh during the period from $15^{\text {th }}$ March 2011 to $28^{\text {th }}$ February 2013. For this purpose 240 admitted patients with conversion disorder satisfying inclusion and exclusion criteria, irrespective of age and gender were consecutively selected as study population. Patients with severe cognitive impairment, mute and stupor were not included in this study. Informed consent was taken from each patient before enrolment in this study. Ethical issues were maintained properly. The respondents were interviewed using data collection sheet containing socio-demographic and other information like age, sex, religion, education, occupation, marital status, social background, socio economic condition etc. which was structured. Psychosocial stressors were assessed subsequently by using life events checklist. The interviews were held in a peaceful and non- threatening environment. After collecting data, editing was done manually and was analyzed with the help of Statistical Package for the Social Sciences (SPSS) software package version 17.

\section{Results}

This study revealed that out of 240 patients, 150 $(62.5 \%)$ were below the age of 25 years. Among all patients $217(90.4 \%)$ were female and 23 (9.6\%) were male (Table 1). Majority of the patients were married $(57.1 \%)$ and their educational status was from class I to primary level (48.8\%). Among the patients, $67.5 \%$ came from joint family, $62.1 \%$ from rural area and $71.7 \%$ from the families with income ranged from 10,000-20,000 BDT per month (Table 2). Out of 217 females 134 $(61.8 \%)$ were housewives, $69(31.8 \%)$ were students, $10(4.6 \%)$ were unemployed, $2(0.9 \%)$ were day laborers and $2(0.9 \%)$ were service holders. Out of 23 males $7(30.4 \%)$ were cultivators, $6(26.1 \%)$ were students, $4(17.4 \%)$ were day laborers, $4(17.4 \%)$ were unemployed and $2(8.7 \%)$ were service holders (Figure 1). Among them $62.5 \%$ patients presented with pseudoseizure whereas $22.9 \%$ experienced mixed symptoms, $11.7 \%$ motor symptoms and $2.9 \%$ sensory symptoms (Figure 2). Psychosocial stressors were clearly identified in $87.5 \%$ of the patients. Among them $32.5 \%$ of the patients, we found more than one stressors (Figure 3).The common stressors in our population in order of frequency were disturbed relation with in-laws $(20.8 \%)$, failure in examination or study problem $(20 \%)$, disturbed relation with spouse (15.4\%), husband staying abroad (13.3\%), love problems (11.2\%), job stress or more work-load (11.2\%) and relationship problem with family members or parents $(9.6 \%)$. Other stressors were pampered child $(3.3 \%)$, demand of marriage $(3.3 \%)$, marriage against will $(2.9 \%)$, death of a close family member $(2.1 \%)$, physical illness $(2.1 \%)$, demand of going abroad (1.7\%), issue less $(1.7 \%)$ and financial crisis $(1.2 \%)$ (Table 3$)$. This table indicated multiple responses by the respondents.

Table 1: Age and gender of the respondents with conversion disorder $(n=240)$

\begin{tabular}{lrrr}
\hline \multirow{2}{*}{$\begin{array}{l}\text { Age } \\
\text { (in year) }\end{array}$} & \multicolumn{2}{c}{ Sex of the patient } & Total (\%) \\
\cline { 2 - 3 } & Male (\%) & \multicolumn{1}{c}{ Female (\%) } & \\
\hline$<15$ & $3(1.2 \%)$ & $24(10.0 \%)$ & $27(11.2 \%)$ \\
$15-24$ & $18(7.6 \%)$ & $105(43.7 \%)$ & $123(51.3 \%)$ \\
$25-34$ & $2(0.8 \%)$ & $48(20.0 \%)$ & $50(20.8 \%)$ \\
$35-44$ & $0(0.0 \%)$ & $24(10.0 \%)$ & $24(10.0 \%)$ \\
$\geq 45$ & $0(0.0 \%)$ & $16(6.7 \%)$ & $16(6.7 \%)$ \\
\hline Total & $23(9.6 \%)$ & $217(90.4 \%)$ & $240(100 \%)$ \\
\hline
\end{tabular}

Table 2: Distribution of total respondents by sociodemographic characteristics $(n=240)$

\begin{tabular}{lr}
\hline Characteristics & Frequency (\%) \\
\hline Religion & $207(86.3 \%)$ \\
Islam & $31(12.9 \%)$ \\
Hinduism & $2(0.8 \%)$ \\
Christianity & \\
Education & $18(7.4 \%)$ \\
No education & $117(48.8 \%)$ \\
I to Primary & $85(35.4 \%)$ \\
VI to SSC & $16(6.7 \%)$ \\
XI to & $4(1.7 \%)$ \\
Graduate and above & \\
Marital status & $137(57.1 \%)$ \\
Married & $98(40.8 \%)$ \\
Unmarried & $5(2.1 \%)$ \\
Divorced/Separated & \\
Types of family & $162(67.5 \%)$ \\
Joint & $78(32.5 \%)$ \\
Nuclear & \\
Social background & $149(62.1 \%)$ \\
Rural & $91(37.9 \%)$ \\
Urban & $56(23.3 \%)$ \\
Socioeconomic status (in BDT) & $172(71.7 \%)$ \\
$<10.000$ & \\
10.000-20,000 & \\
> 20.000 & \\
\hline & \\
\hline
\end{tabular}




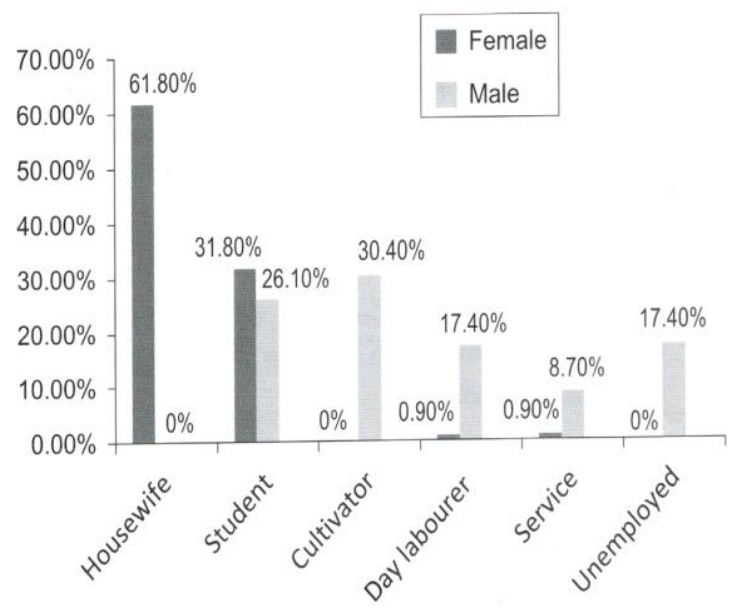

Figure 1: Sex and occupation distribution of the respondents $(n=240)$

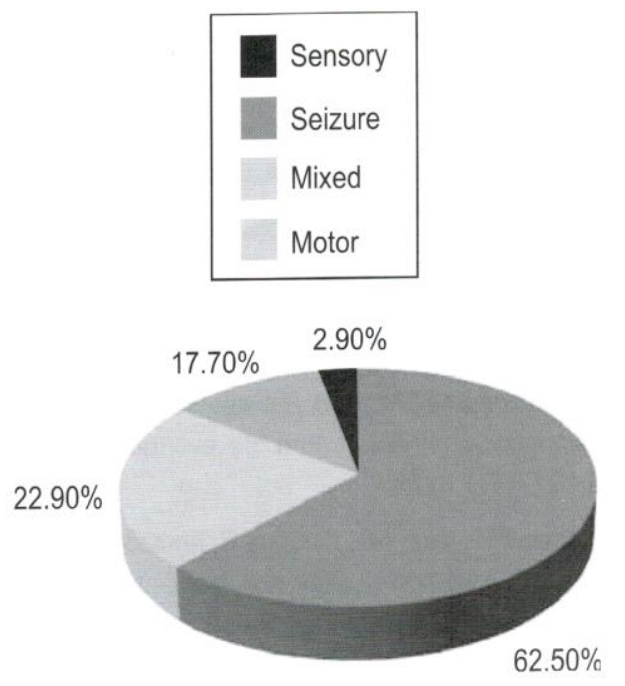

Figure 2: Distribution of the respondents by clinical features $(n=240)$

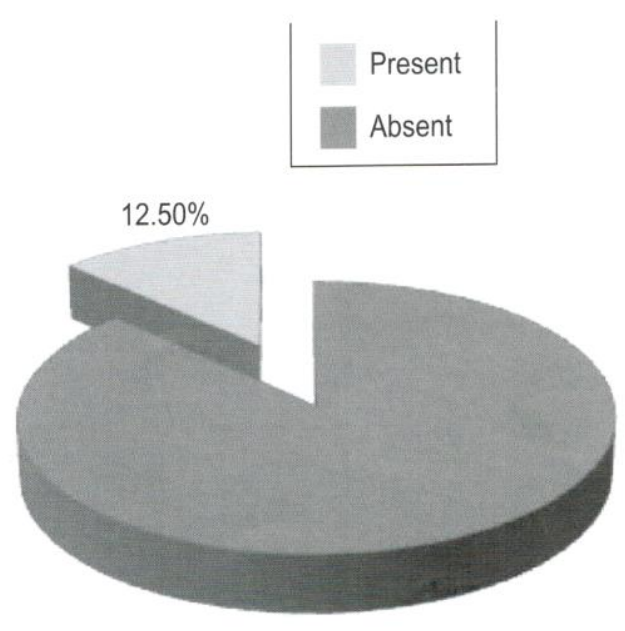

$87.50 \%$

Figure 3: Distribution of psychosocial stressors in subjects $(n=240)$
Table 3: Distribution of respondents on specific stressors/life events $(n=240)$

\begin{tabular}{lcc}
\hline Stressors/Life events & Frequency & Percentage \\
\hline Disturbed relation with in-laws & 50 & $20.8 \%$ \\
Failure in examination or & 48 & $20.0 \%$ \\
study problem & & \\
Disturbed relation with spouse & 37 & $15.4 \%$ \\
Husband abroad & 32 & $13.6 \%$ \\
Love problems & 27 & $11.2 \%$ \\
Job stress or more work-load & 27 & $11.2 \%$ \\
Relationship problem with family & 23 & $9.6 \%$ \\
members or parents & & \\
Pampered child & 8 & $3.3 \%$ \\
Demand of marriage & 8 & $3.3 \%$ \\
Marriage against will & 7 & $2.9 \%$ \\
Death of a close family member & 5 & $2.1 \%$ \\
Physical illness & 5 & $2.1 \%$ \\
Demand of going abroad & 4 & $1.7 \%$ \\
Issue less & 4 & $1.7 \%$ \\
Financial crisis & 3 & $1.2 \%$ \\
\hline
\end{tabular}

\section{Discussion}

The present study revealed that most of the patients with conversion disorder were ranged from 15 to 25 years of age (62.5\%) with female preponderance (90.4\%). This result was similar to a study from Bahawalpur, Pakistan which found that $67.1 \%$ patients were below the age of 21 years and $89 \%$ were female. ${ }^{9}$ In this context another study of Bangladesh found majority of the patient's age ranged from childhood to early adulthood (85.7\%) with female predominance. ${ }^{10}$

In present study, majority of the patients were married and their educational status was class I to primary level. Most of them came from joint family, rural area and from the families with income within 10,000-20,000 BDT per month. In worldwide conversion disorder was also found in more among rural populations, persons with little education, low intelligence and low socio economic groups. ${ }^{11}$ This study found that, among female patients $61.8 \%$ were housewives and $31.8 \%$ were students whereas among male patients $30.4 \%$ were cultivators and $26.1 \%$ were students. In this regards among female patients $77.1 \%$ housewives and $17.1 \%$ students as well as among male patients $33.3 \%$ cultivators and $26.7 \%$ students were found in a study of Peshawar, Pakistan. ${ }^{5}$

On the other hand in our study, $61.3 \%$ of female patients were married which was in line with other studies that showed a high prevalence of psychiatric morbidity in married females. ${ }^{12}$ In present study, the factors favored conversion disorder in married female may be due to constricted relationship with the member 
of in laws house as well as spouse and children where most of the family structure were joint in nature.

The present research pointed out that conversion disorder had strong relationship with the psychosocial stressors. Psychosocial stressors were clearly identified in $87.5 \%$ of the patients. This finding was correlated to a study where $75 \%$ of patients experienced significant stresses immediately before the symptoms. ${ }^{6}$ The common stressors in our study were disturbed relation with in-laws $(20.8 \%)$, failure in examination or study problem (20\%), disturbed relation with spouse $(15.4 \%)$, husband abroad (13.3\%), love problems (11.2\%), job stress or more work-load (11.2\%), relationship problem with family members or parents $(9.6 \%)$. Our findings were similar to that study where $21 \%$ cases had relationship problem with family members, $20 \%$ had examination or study stress, $18 \%$ had romantic relationship problems, $15 \%$ had demanding \& pampered children and $3 \%$ had stresses for engagement break. ${ }^{6}$ On the other hand, some stressors of conversion disorder were common in another study of Bangladesh. But they found some more stressors like sexual problem, dowry, over attention received from grand-parents etc. ${ }^{10}$ In present study, the commonest stressor was relationship problem with either the members of in law's house or husband or other family members. These factors favored for conversion disorder may be due to the patients were restricted by the elder members of in laws house. They can't express their emotion which remain covert and cause psychological conflict. In this study, a large number of stressors were present and identifiable in most conversion disorder's patients. The pattern of stressors in our subjects was unique to our population and most of these stressors were easily treatable.

\section{Conclusion}

Life events and stressors are present in all conversion disorder disorder. So the considerable unrecognized psychopathology in this population highlights the importance of mental health care for conversion disorder and also most important for management of this type of psychiatric disorder.

\section{References}

1. Gelder M, Harrison $P$, Cowen $P$, editors. Shorter oxford textbook of psychiatry. 5th ed. New York: Oxford University Press; 2006. p. 204.

2. American Psychiatric Association. Diagnostic and statistical manual of mental disorders. 4th ed. Washington DC: American Psychiatric Association; 1994. p. 445-69.

3. Lewis A. The survival of hysteria. Psycho Med 1975;5:9-12.

4. Veith I. Hysteria: The history of a disease. 2nd ed. Chicago: University of Chicago Press and Phoenix Books; 1965. p. 54.

5. Irfan N, Badar A. Top ten stressors in the hysterical subjects of Peshawar. J Ayub Med Coll Abottabad 2002;14(4):38-41.

6. Aamir S. Stressful life events in the onset of dissociative (conversion) disorders. J Pak Psych Society 2005;2(2):65-8.

7. Shikura R, Tashiro N. Frustration and fulfillment of needs in dissociative and conversion disorders. Psychiatry Clin Neurosci 2002;56(4):381-90.

8. Nizami A, Mariam $H$, Minhas FA, Najam $N$. Psycho-social stressors in patients with somatoform disorders. J Pak Psych Society 2005;2(1):20-3.

9. Maqsood N, Ali W, Akram B. Patients with conversion disorder: psychosocial stressors and life events. Pak J Med Sci 2010;17(4):715-20.

10. Hossain MD, Siraj NB, Ferdous R, Ahmed HU, Chowdhury MWA. Clinical presentation and risk factors of conversion disorder in Bangladesh. Bang J Psychiatry 2012;26(1):17-25.

11. Sadock BJ, Sadock VA, editors. Kaplan \& Sadock's synopsis of psychiatry: behavioral sciences/clinical psychiatry. 10th ed. New York: Lippincott: Williams \& Wilkins; 2007. p. 634-70.

12. Mumford DB, Minhas FA, Akhtar I, Akhter S, Mubbashar MH. Stress and psychiatric disorder in Urban Rawalpindi Community Survey. $\mathrm{Br} J$ Psychiatry 2000;177:557-62. 